\title{
A Case Control study on the risk factors of Periodontitis"
}

\author{
${ }^{1}$ Dr. Tanzila Rafique, ${ }^{2}$ Dr. Mohammed Sharif Hossain Rasel, ${ }^{3}$ Dr. Md. Nazmul \\ Hasan, ${ }^{4}$ Dr.Shehab Monirul Haque
}

${ }^{1}$ BDS, FCPS, MPH, Medical Officer, Dept. of Orthodontics, BSMMU, Dhaka, Bangladesh; ${ }^{2}$ BDS, MS(Part-II), MPH, Researsh Assistant, Dept. of Conservative Dentistry \& Endodontics, BSMMU, Dhaka, Bangladesh; ${ }^{4} B D S$, MS(Part-II),Dept. of Prosthodontics, BSMMU, Dhaka, Bangladesh; ${ }^{3}$ BDS, FCPS Assitant Professor, Dept. of Orthodontics, Update Dental College \&Hospital, Dhaka, Bangladesh.

\begin{abstract}
Background: Periodontitis is related with certain systemic conditions as well as with some intra oral local factors including patients' oral practices and habits.

Objective: To identify the different risk factors among the patients having Periodontitis.

Methods: A Case control Study was conducted in the rural community in Shirajganj District. Clinically diagnosed patients of periodontitis were being considered as study population.

Results: All the patients had presented with the dental problem of them patients having periodontitis were identified. The diagnosis was based on clinical findings and periodontitis (case) was considered if periodontal pocket depth index score was $2-8$, and no periodontitis if score was ' $0-1$ '. A total of 196 respondents (ranging from 6-80 years) were randomly selected from the community for interview and investigation for periodontal diseases. Data analysis revealed significant association between the age patients, Diabetes mellitus, betel chewing habit, tooth cleansing methods and devices, presence of tooth pricking habits with the development of periodontitis $(p<0.001)$.
\end{abstract}

Conclusion: By delivering the proper and timely health related information raising the awareness level regarding this detrimental disease the overall health status among the population can be improved.

Key words: Periodontitis, Gingivitis, Risk factor.

\section{Introduction:}

To extend the life of teeth either by prevention or by treatment of dental diseases is the major objective of dental care. Main parameter to assess dental health is the mean number of teeth present per person. ${ }^{1}$ It has been well accepted that the number of teeth decreases with age and that carries and periodontal disease are the main causes of tooth loss. The relative impact of these two disease entities may vary in different population groups and geographic areas. ${ }^{2}$ Distribution of dental caries and periodontal disease is almost prevelant throughout the world. ${ }^{3}$ Most studies have found that periodontitis affects a significant number of individuals before the age of 20 years and affects the majority of the adult population after the age of 35-40 years. Studies report that the prevalence and average severity of periodontitis, increased with age for groups of individuals until virtually all middle-aged people had the disease. ${ }^{4,5}$ Data from the studies by Brekhus ${ }^{6}$ and Allen ${ }^{7}$ led many to suppose that the greatest single reason for tooth loss after the age of 40 years was periodontal disease. Later, this was confirmed in a survey in Winnipeg, MB, by Trott and Cross. ${ }^{8}$ However, their results also showed that the percentage of teeth lost because of periodontitis was higher than the percentage of patients who lost teeth because of periodontitis.In other words, with regard to periodontitis, relatively many teeth were lost in relatively few patients. While a large proportion of the population is susceptible to periodontitis, it appears that there is a small segment of the population that is susceptible to severe forms of periodontitis. This observation leads to the proposal that there is susceptibility or risk factors that modulate susceptibility to destructive periodontitis. The susceptibility of individuals appears to vary greatly depending upon which risk factors is operative. ${ }^{9}$ this proposed study is designed to evaluate the different risk factors related with periodontitis among rural people.

\section{Methods:}

It was a case control study. The study was carried out for the period of 6 months from January 2012 to June 2012in the Ullahpara Thana of the Shirajgong district. Patients were selected from the dental camp organized in the Thana Health complex. Clinically diagnosed dental patients having periodontitis were considered as cases and dental patients other than periodontitis were considered as control. 


\section{Selection criteria:}

Inclusion criteria: A total number of 100 cases of periodontitis and 100 healthy controls having the other oral diseases other than periodontitis attended by the doctors from the camp during the study period were enrolled in this study.

\section{Exclusion criteria: \\ I. Patients other than dental diseases \\ II. Patients refused to give the written consent.}

Unwillingness to participate

\section{Sampling Procedure:}

Sampling frame was made over the population. Each of the population had an equal chance of being selected. Simple random sample were generated by using random table, calculator or computer.

\section{Study procedure:}

Study subjects were collected from a rural community of Shirajganj District. Each subjects were completed a questionnaire and were invited to participate in a detailed personal interview and clinical examination in an oral health camp arranged by researcher herself.

The periodontal examinations were undertaken with the use of a lighted mouth mirror and a periodontal probe. All teeth present were examined. Gingival recession was measured on all four surfaces of each remaining tooth. Where root surfaces were exposed, gingival recession was given a positive score; where the gingival margin was coronal to the cemento-enamel junction (CEJ), it was expressed as a negative score. Pocket depth was measured at two sites on all remaining teeth. These were buccal and mesial sites on all teeth except the upper molars, where palatal and mesial sites were probed. The palatal surfaces of upper molars were probed, since these are the sites where the deepest pockets and most attachment loss are often found. A periodontal attachment loss was calculated from the sum of the gingival recession and pocket depth measures and represents the distance from the CEJ to the base of the gingival sulcus or periodontal pocket. As such, it provides a historical record of periodontal disease experience.The examinations were undertaken by researcher herself and field doctors.

\section{Data processing and analysis:}

The SPSS data analysis software was used to perform all statistical analysis (version 15.0, SPSS Inc.). The diagnosis was based on clinical findings and periodontitis (case) was considered if periodntal pocket depth index score was $2-8$, and no periodontitis if score was ' 0 - 1' A total of 196 respondents (ranging from $6-80$ years) were randomly selected from the community for interview and investigation for periodontal diseases. Frequency distribution tables of patients' age, educational status, religion, Demographic characteristics, diabetes profile, chronic diseases, risky behaviors related to periodontitis, brushing habits, tooth cleaning materials, gum pricking habits, Chief complaint, findings from the examination, periodontotis and gingivitis index were constructed and to see the association between each variables data were analyzed by using the Student's t-test and the Chi-square test.

\section{Results:}

The study was carried out in the Ullahparathana of Shirajgong district. About 100 cases and 96 controls were enrolled in the study. The demographic characteristics of the respondents obtained from data analyses are presented in table I. About $70 \%$ of the respondents were 40 or $>40$ years old, $34.7 \%, 40-50$ and $34.7 \% \geq 50$ years old. Majority (93.3\%) of the respondents was Muslim and male female distribution was in the ratio of 1:1. Secondary level educated formed the main bulk followed by non-formal $(25 \%)$ and primary level educated $(22.4 \%)$. Mean $\pm \mathrm{SD}=43.4 \pm 13.61$; range $=6-80$ years.

Over $90 \%$ were married. In terms of occupation, housewife comprised $43.9 \%$, service-holder $28.1 \%$. Other less common occupants were businessman, farmer and student. About $10 \%$ were unemployed. Half of the families consisted of $3-5$ members and $42.9 \% 6-10$ members. About $63 \%$ of the families had monthly income Taka $5-10$ thousands followed by $24.5 \%$ Taka $3-5$ thousands. Very few had income above Taka 10 thousand.

Demographic characteristics of the respondents show that cases were significantly older than their control counterpart $(\mathrm{p}<0.001)$. Females tend to develop periodontitis $(57.9 \%)$ more than the males $(42.1 \%)(\mathrm{p}=$ $0.015)$.

All the respondents with diabetes had periodntitis $(23.7 \%)$ as opposed to none in the control group $(\mathrm{p}=0.015)$. The mean level of blood glucose was significantly higher in the case group $(8.4 \pm 4.02 \mathrm{mg} / \mathrm{dl})$ than that in the control group $(6.5 \pm 0.91 \mathrm{mg} / \mathrm{dl})(\mathrm{p}<0.001)$. 
Association of smoking and betel leaf chewing with periodontitis revealed that there was a significant relationship between betel-leaf chewing and periodntitis. $(\mathrm{p}<0.001)$. But no significant association was observed between smoking and periodontitis $(\mathrm{p}=0.112)$.

Periodontitis was significantly higher among the tooth brush users $(\mathrm{p}<0.015)$. Meswak users were not associated periodontitis $(\mathrm{p}=0.207)$. Finger users were also less prone to develop periodontitis $(\mathrm{p}<0.001)$.

A significantly higher proportion of tooth paste users was observed in case group than that in the control group $(\mathrm{p}=0.001)$, while the tooth powder users less frequently developed periodontitis $(\mathrm{p}<0.001)$. Very few respondents used coal, earth, empty finger and other cleansing materials, as such, a valid comparison was difficult to make.

There was no significant difference between the groups with respect to frequency of tooth cleaning and periodontitis $(\mathrm{p}=0.582)$.

Tooth pricking habit was found to be significantly higher in the case group $(74.6 \%)$ than that in the control group $(45.1 \%)(\mathrm{p}=0.582)$.

Frequency distribution table is made for all types of distribution of the variables and association of periodontitis with all independent variables is seen to yield to the result.

Table I. Association between demographics features and Periodontitis

\begin{tabular}{|c|c|c|c|}
\hline \multirow{2}{*}{ Demographic characteristics } & \multicolumn{2}{|c|}{ Group } & \multirow[t]{2}{*}{ p-value } \\
\hline & $\begin{array}{c}\text { Case } \\
(\mathrm{n}=114)\end{array}$ & $\begin{array}{l}\text { Control } \\
(\mathrm{n}=82)\end{array}$ & \\
\hline Age $^{\text {II }}$ (years) & $47.6 \pm 12.5$ & $37.6 \pm 12.9$ & $<0.001$ \\
\hline \multicolumn{4}{|l|}{$\operatorname{Sex}^{\#}$} \\
\hline Male & $48(42.1)$ & $49(59.8)$ & 0.015 \\
\hline
\end{tabular}

II Data were analyzed using Student's t-Test and were presented as mean \pm SD. \#Data was analyzed using Chi-square $(\chi 2)$ Test.

Table II. Association between Diabetes mellitus and Pereodontitis

\begin{tabular}{lccc}
\hline \multirow{2}{*}{ Diabetes related variables } & \multicolumn{2}{c}{ Group } & \multirow{2}{*}{ p-value } \\
\cline { 2 - 3 } & $\begin{array}{c}\text { Case } \\
(\mathrm{n}=114)\end{array}$ & $\begin{array}{c}\text { Control } \\
(\mathrm{n}=82)\end{array}$ & \\
\hline Known history of $\mathrm{DM}^{\#}$ & $27(23.7)$ & $0(0.0)$ & $<0.001$ \\
\hline Level of random blood glucose & $8.4 \pm 4.02$ & $6.5 \pm 0.91$ & $<0.001$ \\
\hline
\end{tabular}

II Data were analyzed using Student's t-Test and were presented as mean \pm SD. \#Data was analyzed using Chi-square $(\chi 2)$ Test.

Table III. Association smoking and betel leaf chewing habit and Periodontitis

\begin{tabular}{|c|c|c|c|}
\hline \multirow[t]{2}{*}{ Variables } & \multicolumn{2}{|c|}{ Group } & \multirow[t]{2}{*}{ p-value } \\
\hline & $\begin{array}{c}\text { Case } \\
(\mathrm{n}=114)\end{array}$ & $\begin{array}{l}\text { Control } \\
(\mathrm{n}=82)\end{array}$ & \\
\hline Smoking habit $^{\#}$ & $15(13.2)$ & $20(24.4)$ & 0.112 \\
\hline Betel leaf chewing habit ${ }^{i l}$ & $43(37.7)$ & $12(14.6)$ & $<0.001$ \\
\hline
\end{tabular}

\#Data was analyzed using Chi-square $(\chi 2)$ Test. 
Table IV. Association between teeth cleansing materials used and Periodontitis

\begin{tabular}{lccc} 
& \multicolumn{2}{c}{ Group } & p-value \\
\cline { 2 - 3 } Cleansing materials & $\begin{array}{c}\text { Case } \\
(\mathrm{n}=114)\end{array}$ & $\begin{array}{c}\text { Control } \\
\mathrm{n}=82)\end{array}$ & 0.001 \\
\hline Tooth paste & $86(75.4)$ & $43(52.4)$ & $<0.001$ \\
\hline Tooth powder & $29(25.4)$ & $45(54.9)$ & 0.303 \\
\hline Coal & $4(3.5)$ & $1(1.2)$ & 0.418 \\
\hline Earth & $0(0.0)$ & $1(1.2)$ & 0.582 \\
\hline Empty finger & $1(0.9)$ & $0(0.0)$ & 0.582 \\
\hline Others & $1(0.9)$ & $0(0.0)$ & \\
\hline
\end{tabular}

\#Data was analyzed using Chi-square $(\chi 2)$ or Fisher's Exact Test.

Table V. Association between frequency of tooth-cleaning \&Pereodontitis

\begin{tabular}{lcc}
\hline Frequency of tooth cleaning & \multicolumn{3}{c}{ Group } & p-value \\
\cline { 2 - 3 } & $\begin{array}{c}\text { Case } \\
(\mathrm{n}=114)\end{array}$ & $\begin{array}{c}\text { Control } \\
(\mathrm{n}=82)\end{array}$ \\
\hline Once daily & $66(57.9)$ & $44(53.7)$ \\
\hline Twice daily & $43(37.7)$ & $35(42.7)$ \\
\hline 3 times daily & $5(4.4)$ & $3(3.7)$ \\
\hline
\end{tabular}

\#Data was analyzed using Chi-square $\left(\chi^{2}\right)$ Test.

Table VI. Association between tooth pricking habit and Perioodontitis

\begin{tabular}{|c|c|c|c|}
\hline \multirow[t]{2}{*}{ Tooth pricking habit } & \multicolumn{2}{|c|}{ Group } & \multirow[t]{2}{*}{ p-value } \\
\hline & $\begin{array}{c}\text { Case } \\
(\mathrm{n}=114)\end{array}$ & $\begin{array}{l}\text { Control } \\
(\mathrm{n}=82)\end{array}$ & \\
\hline Present & $85(74.6)$ & $37(45.1)$ & $<0.001$ \\
\hline Absent & $29(25.4)$ & $45(54.9)$ & \\
\hline
\end{tabular}

\#Data was analyzed using Chi-square ( $\chi 2)$ Test.

V. Multivariate logistic regression analysis for several risk factors:

Various risk factors like, age, sex, Tooth brushing habit regularly, H/O of tooth/gum pricking habit, bleeding while brushing, pain, Texture, H/O tooth extraction, H/O trauma to tooth, Pus discharge, Bad odors, Sensitivity to tooth, involved area of swelled gum, etc. are associated with Periodontitis. In this study shows that age (hazard ratio 1.086; 95\% CI: 1.033-1.141, $\mathrm{p}<.001$ ), sex (hazard ratio 0.176; 95\% CI: 0.053-0.582, $\mathrm{p}<.004$ ), Tooth brushing habit regularly (hazard ratio .032; 95\% CI: $0.004-0.287, \mathrm{p}<.002$ ), H/O of tooth/gum pricking habit (hazard ratio 4.313; 95\% CI: 1.284-14.490, $\mathrm{p}<.018$ ), Bleeding while brushing (hazard ratio $0.219 ; 95 \%$ CI: 0.050-0.957, p<.044), pain (hazard ratio 0.018; 95\% CI: 0.003-0.100, p<.000), texture (hazard ratio 11.658; 95\% CI: 1.369-99.269, $\mathrm{p}<.025$ ), texture (hazard ratio $15.118 ; 95 \%$ CI: 2.148-106.406, $\mathrm{p}<.006$ ), tooth brush (hazard ratio 7.842; 95\% CI: 0.949-64.781, $\mathrm{p}<.056$ ), H/O tooth extraction (hazard ratio 193.144; 95\% CI: 9.125-4088.282, $\mathrm{p}<.001$ ), H/O trauma to tooth (hazard ratio 23.527; 95\% CI: 2.626-210.803, p<.005), Bad odors (hazard ratio $0.100 ; 95 \%$ CI: $0.026-0.388, \mathrm{p}<.001$ ), Involved area of swelled gum (hazard ratio 0.123 ; $95 \%$ CI: $0.020-0.750, \mathrm{p}<.023)$ are significantly associated with the peridontitis. 
Table: Results from logistic regression analysis

\begin{tabular}{|c|c|c|c|c|c|}
\hline & \multirow[b]{2}{*}{ B } & \multirow[b]{2}{*}{ p-value } & \multirow[b]{2}{*}{ Odds ratio } & \multicolumn{2}{|c|}{ 95.0\% C.I. } \\
\hline & & & & Lower & Upper \\
\hline age & .082 & .001 & 1.086 & 1.033 & 1.141 \\
\hline $\operatorname{sex}(1)$ & -1.737 & .004 & .176 & .053 & .582 \\
\hline Level of blood glucose & .142 & .158 & 1.152 & .947 & 1.403 \\
\hline $\begin{array}{l}\text { History of betel nut, betel leaf and tobacco leaf chewing } \\
\text { habit (1) }\end{array}$ & -.185 & .759 & .831 & .254 & 2.714 \\
\hline Tooth brushing habit regularly (1) & -3.434 & .002 & .032 & .004 & .287 \\
\hline $\mathrm{H} / \mathrm{O}$ of tooth/gum pricking habit (1) & 1.462 & .018 & 4.313 & 1.284 & 14.490 \\
\hline Bleeding while brushing (1) & -1.518 & .044 & .219 & .050 & .957 \\
\hline Bleeding while spiting (1) & .307 & .778 & 1.359 & .162 & 11.409 \\
\hline pain(1) & -4.003 & .000 & .018 & .003 & .100 \\
\hline Texture (1) & 2.456 & .025 & 11.658 & 1.369 & 99.269 \\
\hline Texture (2) & 2.716 & .006 & 15.118 & 2.148 & 106.406 \\
\hline Tooth brush (1) & 2.060 & .056 & 7.842 & .949 & 64.781 \\
\hline Tooth paste (1) & -1.068 & .237 & .344 & .059 & 2.019 \\
\hline H/O tooth extraction (1) & 5.263 & .001 & 193.144 & 9.125 & 4088.282 \\
\hline $\mathrm{H} / \mathrm{O}$ trauma to tooth (1) & 3.158 & .005 & 23.527 & 2.626 & 210.803 \\
\hline Pus discharge (1) & .557 & .558 & 1.745 & .271 & 11.255 \\
\hline Bad odors (1) & -2.302 & .001 & .100 & .026 & .388 \\
\hline Sensitivity to tooth (1) & -.527 & .384 & .591 & .180 & 1.933 \\
\hline Involved area of swelled gum (1) & -2.094 & .023 & .123 & .020 & .750 \\
\hline
\end{tabular}

\section{Discussion:}

This study revealed significant association between the Periodontitis and its risk factors. A risk factor can be defined as an occurrence or characteristic that has been associated with the increased rate of a subsequently occurring disease. It is important to make the distinction that risk factors are associated with a disease but do not necessarily cause the disease.

Ageing is associated with an increased incidence of periodontal disease. ${ }^{14}$ In this study the demographic characteristics of the respondents show that cases were significantly older than their control counterpart $(\mathrm{p}<$ $0.001)$

Diabetes is a modifiable factor in the sense that though it cannot be cured, it can be controlled. ${ }^{11}$ In our study more than $60 \%$ of the respondents did not know whether they were diabetic or not.Of them 27 were known about their diabetes, only 1(3.7\%) adopted control measures. The mean random blood glucose was $7.6 \pm$ $3.2 \mathrm{~mol} / \mathrm{L}$. Over $60 \%$ of those who had diabetes used to receive oral hypoglycemic agents and $38.5 \%$ followed diet control

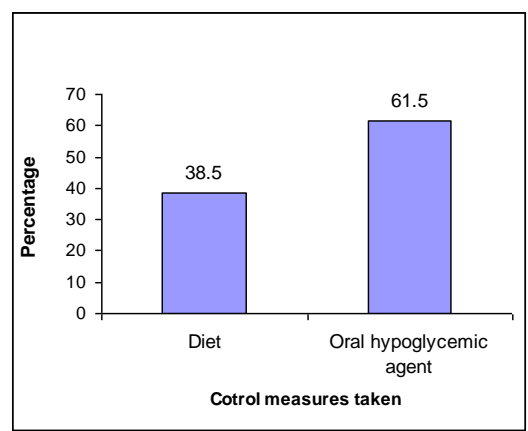

Fig.: Distribution of respondents by control measures taken
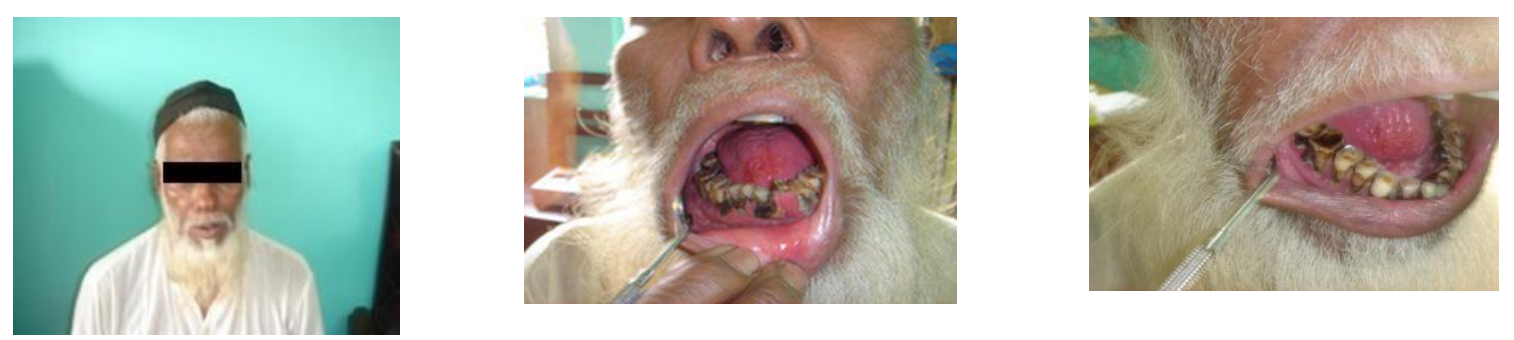

Fig: Oral condition of a70 year's old patient with uncontrolled Diabetes mellitus

Of the total 196 respondents, 23(11.7\%) had hypertension; of them 13(56.5\%) achieved control over the disease.

Only 2 respondents had coronary heart disease (CHD). 
The relationship between smoking and periodontal health was investigated as early as the middle of the last century. More recently a wealth of epidemiological, clinical and in vitro studies have emerged that have provided irrefutable evidence that smoking negatively impacts periodontal health and propose mechanisms by which this may occur. ${ }^{15}$ In our study out of 196 respondents, only 6(3.1\%) were current smoker, $29(14.8 \%)$ were past smoker and $161(82.1 \%)$ were non-smokers. For current smokers, the mean duration of smoking and the average number of sticks smoked per day and for the past smokers, years before smoking quitted.

All but one had tooth-brushing habit. Of them majority (97.4\%) maintained regularity in brushing tooth. About $88 \%$ brushed their teeth in the morning after getting up from the bed, $42.1 \%$ at night before going to bed. Very few $(5.1 \%)$ had habit of brushing after lunch. Over 55\% of the patients cleaned their teeth once daily, $39.8 \%$ twice daily and $4.1 \% 2$ or $>2$ times daily (Table V). Device used for tooth cleansing shows that about three-quarters (74\%) of the respondents brushed their teeth using tooth-brush followed by finger (22.5\%), meswak $(5.6 \%)$ and tree-leaf $(0.5 \%)$.

Nearly two-thirds $(65.8 \%)$ of the respondents used tooth-paste as tooth cleansing material, $37.8 \%$ tooth-powder and $2.6 \%$ coal.

More than $62 \%$ of the respondents had tooth/gun pricking habit. Of them $54.1 \%$ did this after each meal, $16.4 \%$ after eating meat, $21.3 \%$ had no specific time for pricking and $8.2 \%$ pricked subconsciously. As material used for pricking is considered, $98.4 \%$ used wooden sticks and the rest $(1.6 \%)$ used threads.

There are a variety of treatments for gum disease depending on the stage of disease, how person may have responded to earlier treatments, and overall health.Treatments range from nonsurgical therapies that control bacterial growth to surgery to restore supportive tissues. In our findings nearly half $(46.4 \%)$ of the respondents exhibited bleeding after mild pressure over gum or touching the gum margin with delicate materials, $8.2 \%$ showed pus discharged, $34.7 \%$ had bad odor, $54.6 \%$ had sensitivity to tooth and $20.4 \%$ had swelled gum. Nearly two-thirds respondents had gingivitis index and calculus index 2. Majority (94.4\%) of the respondents had periodontal pocket depth index from $1-8$ (periodontitis) Moderate periodontitis (score 2) was observed in $43.4 \%$ of the respondents, mild (score 1) in $36.2 \%$ respondents (score $6-8$ ) and advanced in $14.8 \%$ respondents. Over half $(53.6 \%)$ of the respondents exhibited pinkish gingival followed by $28.6 \%$ reddish, $15.8 \%$ blackish and $2 \%$ having no uniform colour everywhere. In terms of texture, two-thirds (66.8\%) had rough gingival margin, $24.5 \%$ had ulceration of the gingival and $8.7 \%$ had normal * healthy gum.

\section{Conclusion:}

This study found significant association between the Periodontitis and the factors considering as the cause of its development. The susceptibility to periodontal disease may be the result of defects in neutrophil function. The approach to the diagnosis and treatment of periodontal disease is changing. The disease has not changed, but dentistry's understanding of the pathogenesis and appreciation for the influence of host factors has improved. As a result, the approach to the management of the disease is evolving. Future studies will likely be focused on understanding the relationship between genetic and environmental factors and also on the rapid and practical identification of at-risk individuals, and will allow us to tailor therapy to more closely suit the needs of our patients as individuals and thus achieve better results.

\section{References:}

[1]. Sheiham A, Hobdell MH, Cowell CR. Patterns of tooth loss in British populations. Studies on industrial populations. Br Dent J 1969; 126: 255-60.

[2]. Lo"e $\mathrm{H}, \mathrm{A}^{\circ}$ nerudA ${ }^{\circ}$, Boysen $\mathrm{H}$, Smith $\mathrm{M}$. The natural history of periodontal disease in man. The rate of periodontal destruction before 40 years of age. J Periodontol 1978; 49: 607-620.

[3]. Russell AL. Epidemiology of periodontal disease. Int Dent J 1967;17: 282-296.

[4]. Scherp HW. Current concepts in periodontal disease research: epidemiological contributions. J Am Dent Assoc 1964; 68: 667-675

[5]. Brown LJ, Lo"e H. Prevalence, extent, severity and progression of periodontal disease. Periodontology 2000 1993; 2: 57-71.

[6]. Brekhus PJ. Dental disease and its relation to the loss of human teeth. J Am Dent Assoc 1929; 16: 2237-2247.

[7]. Allen EF. Statistical study of the primary causes of extractions. J Dent Res 1944; 23: 453-458.

[8]. Trott JR, Cross HG. An analysis of the principle reasons for tooth extractions in 1813 patients in Manitoba. Dent Pract 1966; 17: 2027.

[9]. Genco RJ. Current view of risk factors for periodontal diseases. J Periodontol 1996; 67: 1041-1049.

[10]. Ogawa H, Yoshihara A, Hirotomi T, Ando Y, Miyazaki H. Risk factors for Periodontal disease progression among the elderly. J ClinPeriodontol 2002: 29: 592-97.

[11]. Gonza'lez YM, Nardin, AD, Grossi SG, Machtei EE, Genco RJ, Nardi, ED. Serum cotinine levels, smoking, and periodontal attachment loss. Journal of Dental Research 1996; 75, 796-802.

[12]. J IntAcad ,Periodontol. Risk Factors for Periodontitis.2005 January; 7(1): 3-7.

[13]. Perry R. Klokkevold, DDS, MS,Periodontal Medicine: Assessment of Risk Factors for Disease. Copyright 1999 Journal of the California Dental Association.

[14]. Grossi, 1994; Grossiet al., 1995. J Periodontol, 1995 Jan; 66(1): 23-9.

[15]. Albandar, 2000 Dec. J Periodontol. 71(12): 1874-81. 